\title{
A Case Study of Nematode Communities' Dynamics along Successional Paths in the Reclaimed Landfill
}

\author{
George P. Stamou ${ }^{1}$, Maria D. Argyropoulou ${ }^{2}$, Ignacio Rodriguez-Polo ${ }^{3}{ }^{\circ}$, George Boutsis ${ }^{1}$, \\ Pantelitsa Kapagianni ${ }^{1}$ (D) and Efimia M. Papatheodorou ${ }^{1, *}$ \\ 1 Department of Ecology, School of Biology, AUTH, 54124 Thessaloniki, Greece; \\ gpstamou@bio.auth.gr (G.P.S.); gboutsis@bio.auth.gr (G.B.); Kapagianni@gmail.com (P.K.) \\ 2 Department of Zoology, School of Biology, AUTH, 54124 Thessaloniki, Greece; margyrop@bio.auth.gr \\ 3 Faculty of Biological Sciences, Complutense University of Madrid, José Antonio Novais 12, \\ Ciudad Universitaria, 28040 Madrid, Spain; IRodriguezPolo@dpz.eu \\ * Correspondence: papatheo@bio.auth.gr; Tel.: +30-231-099-8313
}

Received: 14 April 2020; Accepted: 6 July 2020; Published: 9 July 2020

\begin{abstract}
We assessed the abundance and composition of nematode communities in soil under herbaceous vegetation in reclaimed landfill sites at different ages after closure (3,10 and 14 years) compared to those in neighboring semi-natural grazed grasslands (reference sites). We further applied network analysis based on the co-occurrence patterns of nematodes. Nematode abundance decreased between 3 and10 years of regeneration, but significantly increased from 10 to 14 years of regeneration. The number and identity of genera were comparable along the succession; however, there were dissimilarities in community composition during early- and mid-succession. The diversity, community composition and abundance at the sites after 14 years of regeneration converged with those at the reference sites. Moreover, changes during succession were not accompanied by the maturation of the soil food web, as demonstrated by Enrichment and Channel indices. In all the networks, centrality and modularity metrics differed significantly from those for random networks, whereas cohesion metrics showed no difference. All the networks exhibited Small-worldness indices higher than one, demonstrating that the networks of the interactions among genera at all the sites shared features that matched both random and non-random networks. The succession trajectory in reclaimed landfills was represented by a sequence of changes that differed in relation to the variable under consideration; network parameters tended to converge with those of a relatively resistant reference community, while the Enrichment and Channel indices did not. Additionally, the succession trajectory was not linear or steady; only the Channel index and Worldness index showed linear responses to succession time. However, across all the successional stages, the resource status remained basal or degraded while the nematode communities had an enhanced ability to cope with sudden changes.
\end{abstract}

Keywords: trophic complexity; scale effects; resource limitation; environmental constraints; determinism vs. stochasticity

\section{Introduction}

Since the field of ecological succession was established, this process has been modeled as the progressive and directional change in the structure and the dynamics of biological communities [1]. However, recent mainstream models tackle succession as a complex procedure leading to polyphasic and frequently unpredictable outcomes [2,3]. This is because a plethora of factors contribute to the routes of succession, which are grouped into three main categories: environmental constraints, species autoecology, and species interactions [2]. 
Nematodes are considered reliable biological indicators for monitoring the course of succession, since they are a numerically important component of soil fauna, colonize a large array of soil types and modulate the operation of key links in soil food webs [4,5]. Moreover, nematode genera cover the whole range of $\mathrm{r}-\mathrm{K}$ life strategies, which makes their community ideal for ecological succession studies such as long-term soil reclamation studies. Studies that used nematode communities as tools to depict the route of restoration under different restoration schemes [6-9] focused on nematode abundance, diversity and functional indices. This is because nematodes are assumed to reflect (at least to some extent) the maturity level of the community and its ability to cope with disturbance events [10-12]. However, patterns in abundance reflect the numerical responses of different taxa to common environmental factors, rather than biotic interactions or the interactions of biota with abiotic factors [13].

Here, we followed the course of ecological succession within the framework of a project that was launched to reclaim landfill sites. Specifically, we studied the trajectory of the secondary succession of the nematode community in a reclaimed waste landfill that contained sections of different ages after closure. Reclamation schemes are designed to establish species associations and ecosystem functions progressively analogous to those of neighboring natural undisturbed sites [14]. However, the restoration process in reclaimed landfills differs from typical primary succession processes. This is because reclaimed landfills are initially covered with transported soil carrying associated seeds [15] and faunal and microbial banks from the sources of origin. To add information generated by assessing abundance and diversity only, here, we coupled common analytical techniques for evaluating abundance, diversity and functional indices with techniques used in social network analysis, accounting for interactions among nematode genera. Proulx et al. [16] observed that the structure of the assemblages of coexisting biota is effectively modeled as a network of nodes, representing taxonomic units, while linkages represent the interactions among them. In particular, by applying network analysis, we aimed to highlight the usefulness of small-world properties that facilitate the evaluation at the level of the entire network and local clusters simultaneously [17]. Few studies have used network analysis to explore the relationships between nematode genera. Exceptions include Zhang et al. [18] and Kapagianni et al. [19], who studied the effect of fertilization and disinfection regimes, respectively, on the relationships between nematode genera. To the best of our knowledge, studies applying network analysis to nematode communities to assess the route of succession do not exist yet.

Through combining these two methodological approaches, we expected to identify components relating to the directness of the succession process and the resistance of nematode communities to changes. We hypothesized that the evolvement of the nematode community along the secondary succession trajectory would follow a linear and continuous pattern of change, with the community in the nearest natural ecosystem representing the endpoint, and would be reflected in both quantitative (abundance, diversity and functional indices) and qualitative (community composition and relationship between the genera) community attributes.

\section{Materials and Methods}

\subsection{Study Site}

This study was conducted at Tagarades landfill $\left(40^{\circ} 27^{\prime} 30^{\prime \prime}\right.$ to $40^{\circ} 28^{\prime} 30^{\prime \prime} \mathrm{N}$ latitude, $23^{\circ} 2^{\prime} 30^{\prime \prime} \mathrm{E}$ longitude, $120-180 \mathrm{~m}$ a.s.l.), which is located about $21 \mathrm{~km}$ to the south-southeast of the city center of Thessaloniki, Greece (straight-line distance). The area surrounding the Tagarades landfill site is mainly agricultural and urban, with semi-natural vegetation of dry grasslands and thickets of Quercus coccifera shrubs along the boundary.

The Tagarades landfill was active from 1981 to 2008 and primarily received domestic waste from Thessaloniki city. The landfill included sections that were filled at different times. The areas in the first (10 ha in total; R14, representing the late stage of succession), second (19 ha in total; R10, mid stage 
of succession) and third (40 ha in total; R3, early stage of succession) were saturated in 1998, 2002 and 2009, respectively (Figure 1). After reaching capacity, the different sections were covered with geotextile and aluminum sheets, followed by a surface soil layer of about $1 \mathrm{~m}$ depth, which originated from nearby sites and was used to establish vegetation. Finally, an irrigation system and a system for the collection of leachates and biogases was installed.

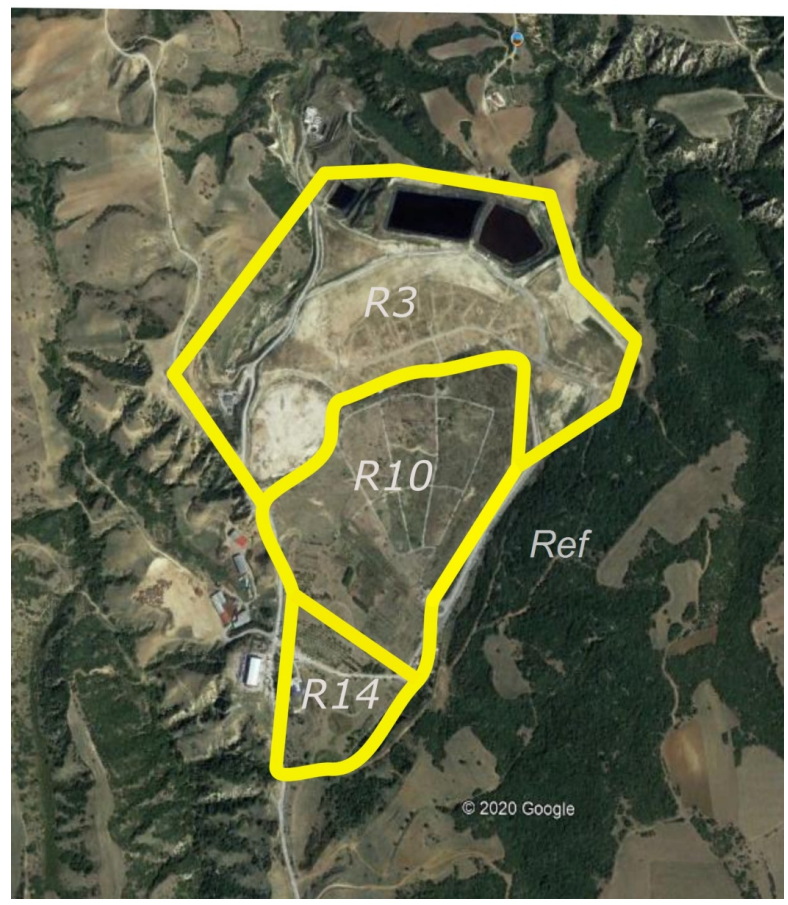

Figure 1. Map of the reclaimed areas of different ages (R3: 3-yrs, R10; 10-yrs and R14; 14-yrs) and the reference site (Ref).

Data on the composition of the herbaceous community in the reclaimed and reference areas were collected one year before this study and were presented in Papatheodorou et al. [20]. Table S1 presents the most abundant herbaceous species recorded in each area.

\subsection{Experimental Design and Nematode Sampling}

In September 2012, soil was sampled in the reclaimed sections of different ages after closure (3, 10 and 14 years), as well as in the neighboring natural grasslands. Because of the management history (grazing) of the wider area, grasslands were considered representative of the final stage of the succession process and were used as the control. We only collected soil samples from areas covered with herbaceous vegetation (not planted), following a split-plot experimental design. According to Chatzoudis [21], soil texture was similar across all the sites (sandy clay loam soil; clay ranged from 25 to $30 \%$, silt ranged from 16 to $22 \%$ and sand ranged from 44 to $52 \%$ ). Additionally, there was no differentiation in the organic matter between the sites, while the $\mathrm{pH}$ ranged from 7.4 to 8.2.

For the three categories, we defined three plots $\left(100 \times 100 \mathrm{~m}^{2}\right)$. In each plot, we randomly chose three subplots of $50 \times 50 \mathrm{~m}^{2}$ covered by herbaceous plants. Inside each subplot, five soil samples were taken at random from the upper $20 \mathrm{~cm}$ of the soil layer with a core sampler of $3 \mathrm{~cm}$ diameter. These samples were mixed together to generate a composite sample. Thus, a total of nine composite soil samples was collected from each section category. The same experimental design was used for the seminatural grasslands, which were located on land adjacent to the landfill. Therefore, our experimental design contained three categories of the restored sections and the control. 
Nematodes were extracted from $200 \mathrm{~mL}$ of each composite soil sample. Before taking this subsample, the soil was gently mixed by hand and the soil aggregates were broken up. For extraction, we used the modified Cobb's sieving and decanting method proposed by S'Jacob and van Bezooijen [22], in which a cotton-wool filter was used in the last step. After counting the total abundance of the nematodes, we fixed them with $4 \%$ formaldehyde. Subsequently, we randomly selected at least 100 nematodes from each sample and identified them to the genus level, with reference to Bongers [23].

\subsection{Community Composition Analysis}

To assess the diversity of the nematode communities, we used the method of diversity ordering described by [24], which is based on Rényi's index [25]. Rényi's parametric index of order $a$ shows varying sensitivity to the rare and abundant species in a community, as the scale of parameter $\alpha$ changes [26]. For each community, it provides a profile of the most widely used diversity indices. For $a=0$, the index equals $\log$ species number; for $a=1$, it equals Shannon's index; and for $a=2$, it equals Simpson's index. For a tending to infinite, the index is most sensitive to the abundant species of a community. Thus, when two diversity profiles differ for a range of small $a$ values, this is due to the number of genera. For a range of large $a$ values, the differences between communities are driven by the presence of abundant genera. When two diversity profiles intersect, the two communities may be ordered differently by different diversity indices. For the calculations, we used DivOrd [27].

Nematode taxa were classified to trophic guilds according to Yeates et al. [28] and assigned a colonization-persistence value ( $c-p$-values) according to Bongers [29] and Bongers and Bongers [30]. Then, the maturity index (MI) for the free living nematodes and the plant parasitic index (PPI) for the plant feeding nematodes were calculated according to Bongers [29]. Functional faunal analysis was used to generate the Enrichment Index (EI), Structure Index (SI) and Channel Index (CI) according to Ferris et al. [31].

\subsection{Network Analysis}

Network analysis aims to represent and quantify structures, borrowing metrics from graph theory, which is a field of mathematics analyzing the patterns of linkages (edges) among entities (nodes; [32]). Nodes represent genera, and linkages represent how one genus is related to another, while the network map represents how the associative spatial relationships are organized. The analysis begins with the construction of a valued community matrix based on the joint occurrence, estimated by employing the MacArthur and Levins [33] index:

$$
M_{i j}=\frac{\sum_{1}^{n} p_{i k} p_{j k}}{\sum_{1}^{n} p_{i k}^{2}}
$$

where $n$ is the number of samples, and $p_{i k}$ and $p_{j k}$ are the proportional abundances of genera $i$ and $j$ in the sample $k$, respectively. Initially, the index was devised for the purpose of measuring the niche overlap. Specifically, $p_{i k}$ measures the proportion of a common resource $k$ that is used by genus $i$, and $p_{j k}$ measures the proportion of resource $k$ that is used by genus $j$. Thus, $M_{i j}$ estimates the extent to which the niche space of genus $i$ overlaps that of genus $j$. If genus $i$ exploits part of resources exploited by the genus $j$, then the resource space of $i$ is completely overlapped, whereas for genus $j$, the overlap is partial. Measures of the joint occurrence of genera are supposed to reflect the intensity of competitive interaction between genera [33]. However, as this phenomenon has not been empirically quantified for nematode genera, we consider the $M_{i j}$ values to reflect not only competitive but any kind of relationship between genera. Since the effect of genus $i$ on genus $j$ did not have the same magnitude compared to the effect of $j$ on $i$, the community matrix was not symmetrical. To calculate a threshold above which the effects would not be considered negligible, the desired relative error was set at 0.2 for confidence level $a=0.05$, which is an acceptable value for sampling soil organisms [34]. Then, given the number of sampling units, we applied a method to increase the threshold gradually to the point where the relative error had reached the desired value of 0.2. For all the networks, the estimated 
threshold values were up to $20 \%$ of the community's maximum value, which was used as a general rule. Thus, if the $M_{i j}$ value was below $20 \%$ of the community's maximum, the effect of the genus $i$ on the genus $j$ was considered negligible, and the corresponding entry in the matrix was set to zero.

Community matrices were constructed separately for each nematode community and were further analyzed using the network analysis software UCINET 6 [35]. Real-valued data were used to estimate variables referring to the strength of relationships, such as density, in and out centralities and structural equivalence.To estimate variables referring to the number of links, such as the shortest path and clustering coefficients, external minus internal links (E-I), and effective size, the binary version of the community matrix was automatically created by UCINET 6as required. For $M_{i j}$, the elements of the valued network were set to 0 if the nodes $i$ and j were not connected; otherwise, they were set to 1 . In the resulting graphs, the nodes representing nematode genera and linkages represent interactions among genera, which were depicted by employing a circular layout [36]. To check departure from randomness in the values of the shortest path, clustering coefficient and effective size values, 999 additional binary Erdös-Rényi random networks with a number of nodes and average number of linkages equal to those of the experimental networks were created and analyzed in a similar way. The outputs of the experimental networks were tested against those provided by the random networks, using the $z$-test.

Cohesion assesses the extent of the connectedness of a network [37,38], and clustering refers to the tendency of nodes towards bundling [39], while ego properties represent the structural importance of a given node by evaluating the extent to which it hasa more influential position than another node [40]. Then, we examined whether our networks fell into the class of small-world networks. According to Humphries and Curney [41], a real-world network falls into the class of small-world networks if the shortest path $\left(L_{\text {real }}\right)$ estimated for the real network is more or less equal to the shortest path $\left(\mathrm{L}_{\text {rand }}\right)$ estimated for an equivalent random network $\left(L_{\text {real }} \approx L_{\text {rand }}\right)$ and when the clustering coefficient estimated for the real network $\left(\mathrm{Cl}_{\text {real }}\right)$ is much higher than that for an equivalent random network $\left(C l_{\text {real }} \gg C l_{\text {rand }}\right)$, i.e., if $S=\left(C l_{\text {real }} / C l_{\text {rand }}\right) /\left(L_{\text {real }} / L_{\text {rand }}\right)>1$.

Furthermore, we used the relevant algorithm of UCINET 6 to partition nodes to clusters considering roles and positions [42]. The role or position of a node is established by means of its relationshipswith other participants. We identified classes of structurally equivalent nodes (Table 1 ). The fitting of the real-world data to a structurally equivalent model was assessed by estimating the R-squared correlation coefficient. Additionally, the value of the clustering coefficient E-I was calculated as the number of links external to clusters minus the number of links that are internal to clusters divided by the total number of links [43].To assess the structural importance and/or influence of each node, we estimated the degree centrality that complied with bidirectional interconnections. Given the community matrix, the output and input centralities were estimated for each node, representing its importance and influence, respectively. To estimate the output centralities of a node $i$, only the outgoing links were considered, while the input centralities of $i$ were estimated using the incoming links. Finally, we took into account the fact that the net impact of a node (ego) depends on the number of nodes with which it interacts directly (alters) but is constrained by the number of direct interactions between alters [42]. Then, we estimated the effective size of each node as the number of nodes with which it was directly interacting minus the average number of ties that alters have between themselves. 
Table 1. A layout of the properties and metrics referring to the architecture of the network.

\begin{tabular}{|c|c|c|}
\hline Category & Metrics & Explanation \\
\hline \multirow{4}{*}{$\begin{array}{l}\text { Cohesion; Assesses the } \\
\text { extent of connectivity of the } \\
\text { entire network }\end{array}$} & Density & $\begin{array}{l}\text { For binary non-symmetric data, density equals the number } \\
\text { of links directed to a node plus the number of links } \\
\text { starting from that node, divided by the total number of } \\
\text { links. For valued data, density equals the total of all values } \\
\text { divided by the number of links. Lower overall values } \\
\text { indicate enhanced complexity. }\end{array}$ \\
\hline & Shortest path length & $\begin{array}{l}\text { The distance between two nodes is the number of links } \\
\text { contained in the shortest path that connects them. Lower } \\
\text { overall values indicate preponderance of indirect links. }\end{array}$ \\
\hline & Clustering Coefficient & $\begin{array}{l}\text { Measures how much the neighbors of each node are also } \\
\text { neighbors of each other. The clustering coefficient of a } \\
\text { node is the density of its open neighbors. The overall } \\
\text { clustering coefficient is the mean of the clustering } \\
\text { coefficient of all nodes. }\end{array}$ \\
\hline & $\begin{array}{l}\text { Structurally equivalent } \\
\text { groups }\end{array}$ & $\begin{array}{l}\text { Partition of nodes into clusters. Nodes belonging to the } \\
\text { same group exhibit similarity in their connection profile } \\
\text { with the other counterparts in the cluster. }\end{array}$ \\
\hline \multirow{3}{*}{$\begin{array}{l}\text { Modularity;assesses the } \\
\text { possibility of various nodes } \\
\text { to be grouped together }\end{array}$} & R-square & $\begin{array}{l}\text { This accounts for the correlation between the partitioned } \\
\text { data matrix and an ideal matrix with the same dimension. } \\
\text { Each cell in the cluster of the ideal matrix is set to the } \\
\text { average value of the corresponding cluster in the } \\
\text { data matrix. }\end{array}$ \\
\hline & E-I index & $\begin{array}{l}\text { The number of links external to the cluster minus the } \\
\text { number of links that are internal to the cluster divided by } \\
\text { the total number of links. This reflects the compactness of } \\
\text { the network. }\end{array}$ \\
\hline & Small-world & $\begin{array}{l}\text { A real network is a small-world network if it has a similar } \\
\text { mean shortest path length but greater clustering coefficient } \\
\text { compared to a random network with the same number of } \\
\text { nodes and average density. }\end{array}$ \\
\hline \multirow{2}{*}{ Ego properties } & Degree Centrality & $\begin{array}{l}\text { The sum of the values of the links. The normalized values } \\
\text { equal to (number of nodes-1) multiplied by max value. }\end{array}$ \\
\hline & $\begin{array}{l}\text { Effective size(assesses } \\
\text { structural holes) }\end{array}$ & $\begin{array}{l}\text { The number of ties that a node has with its neighbors, } \\
\text { minus the average number of ties that these neighbors } \\
\text { have between themselves. }\end{array}$ \\
\hline
\end{tabular}

\subsection{Statistical Analyses}

To test the effect of the reclamation age on the nematode abundances and functional indices, we applied one-way ANOVA. In cases in which the assumptions of the ANOVA were not met (normal distribution, and independence among means and variances), the data were transformed properly. To investigate similarities in the composition of the communities during succession, one-way PERMANOVA (permutation $n=999$ ) was applied on Bray-Curtis distance measures (PAST software). When one-way ANOVA or PERMANOVA identified significant effects, a Least Square differences (LSD) test was applied to detect differences among sites. The non-replicated values of the shortest path and clustering coefficient were compared against those of random neutral networks.

\section{Results}

\subsection{Community Composition}

Thirty-two nematode genera were recorded in our study area. One-way ANOVA showed that the total abundance of nematodes and the abundance of different trophic groups differed significantly according to the number of years of reclamation (Figure 2). 


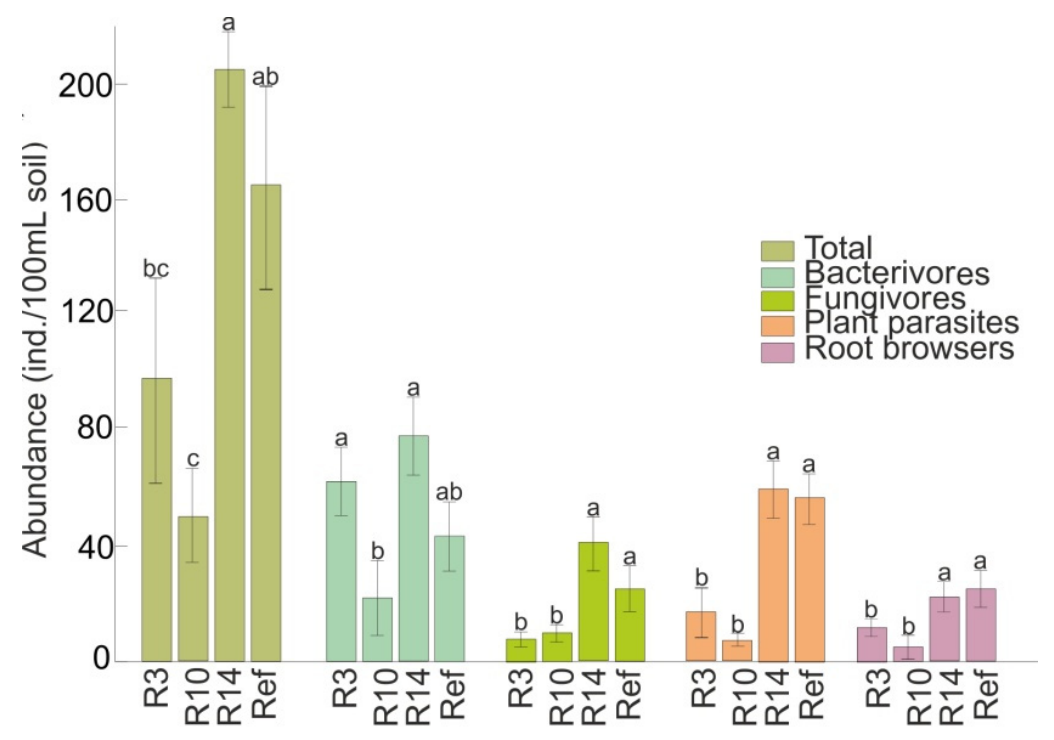

Figure 2. Abundance of different nematode trophic groups in relation to reclamation age. Different letters are used to depict significant differences between sites according to an LSD test.

In general, abundance tended to increase with the number of years of reclamation, with the exception of the abundances of omnivores and predators, which remained stable. In particular, the abundance of fungivores, plant parasites and root-hair feeders was similar to that of the reference community. Bacterial feeding genera Acrobeloides and Chiloplacus dominated R3 (the most recently reclaimed site) (Figure S1). At the other two reclaimed sites, the phytoparasite Helicotylenchus was the most abundant, with numbers progressively increasing towards those documented at the reference site. A relatively high abundance of Aphelenchus (fungivore) and Filenchus (root-hair feeder) was documented at R10, R14 and the reference sites as well.

The composition of the nematode community differed with the number of years of reclamation $\left(\mathrm{F}_{3,28}=4.06, p=0.0001\right.$; Table 2). Pairwise post hoc comparisons showed that R14 communities converged with those of the reference sites.

Table 2. F- and $p$-values of a one-way PERMANOVA test on nematode community data to check for similarities in community composition between landfill sections and the adjacent reference sites.

\begin{tabular}{cccccccccc}
\hline \multirow{2}{*}{ Sampling Sites } & \multicolumn{2}{c}{ R3 } & \multicolumn{2}{c}{ R10 } & \multicolumn{2}{c}{ R14 } & \multicolumn{2}{c}{ Ref } \\
\cline { 2 - 10 } & $\mathbf{F}_{3,28}$ & $p$ & $\mathbf{F}_{3,28}$ & $p$ & $\mathbf{F}_{3,28}$ & $p$ & $\mathbf{F}_{3,28}$ & $p$ \\
\hline R3 & & & & 4.94 & 0.002 & 4.21 & 0.001 & 4.00 & 0.001 \\
R10 & & & & & & 7.40 & 0.000 & 6.61 & 0.000 \\
R14 & & & & & & & & 0.91 & 0.470 \\
\hline
\end{tabular}

Regarding nematode indices, one-way ANOVA showed that the maturity index, plant parasite index and structure index displayed non-significant differences between the restored and the reference sites (Tables S4-S6). These three parameters were 2.0-2.2, 2.6-2.8 and 20-30, respectively. By contrast, the enrichment and channel indices varied significantly over the course of succession (Figure 3; Tables S2 and S3). The highest CI values were recorded in the oldest reclaimed site (R14) and the reference sites. The lowest EI values corresponded to the oldest reclaimed site (R14), while no differences in the EI values were recorded between the rest of the sites. 


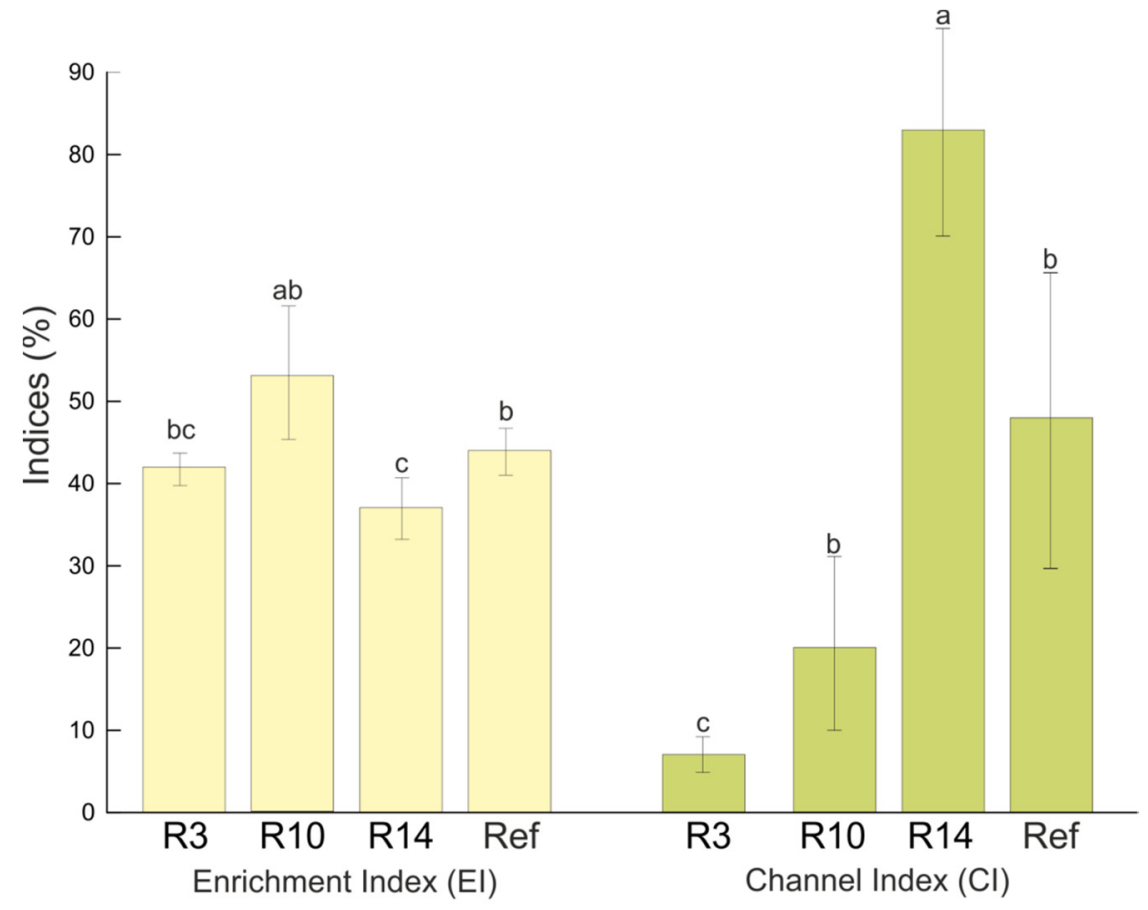

Figure 3. Enrichment Index and Channel Index in the three reclaimed sections (R3, R10 andR14) and references sites (Ref) ( $n=9$, mean \pm standard. error). Different letters are used to depict significant differences between sites according to an LSD test.

The diversity profiles exhibited slight differences in the number of taxa (corresponding to $a=0$ ) (Figure 4) However, the Shannon and Simpson diversity indices (corresponding to $a=1$ and $a=2$, respectively) and equitability (indicated by $a>2$ ) were higher in R3 and R10 compared to in the reference community. By contrast, the diversity in R14 was comparable to that in the reference site, which had the lowest diversity.

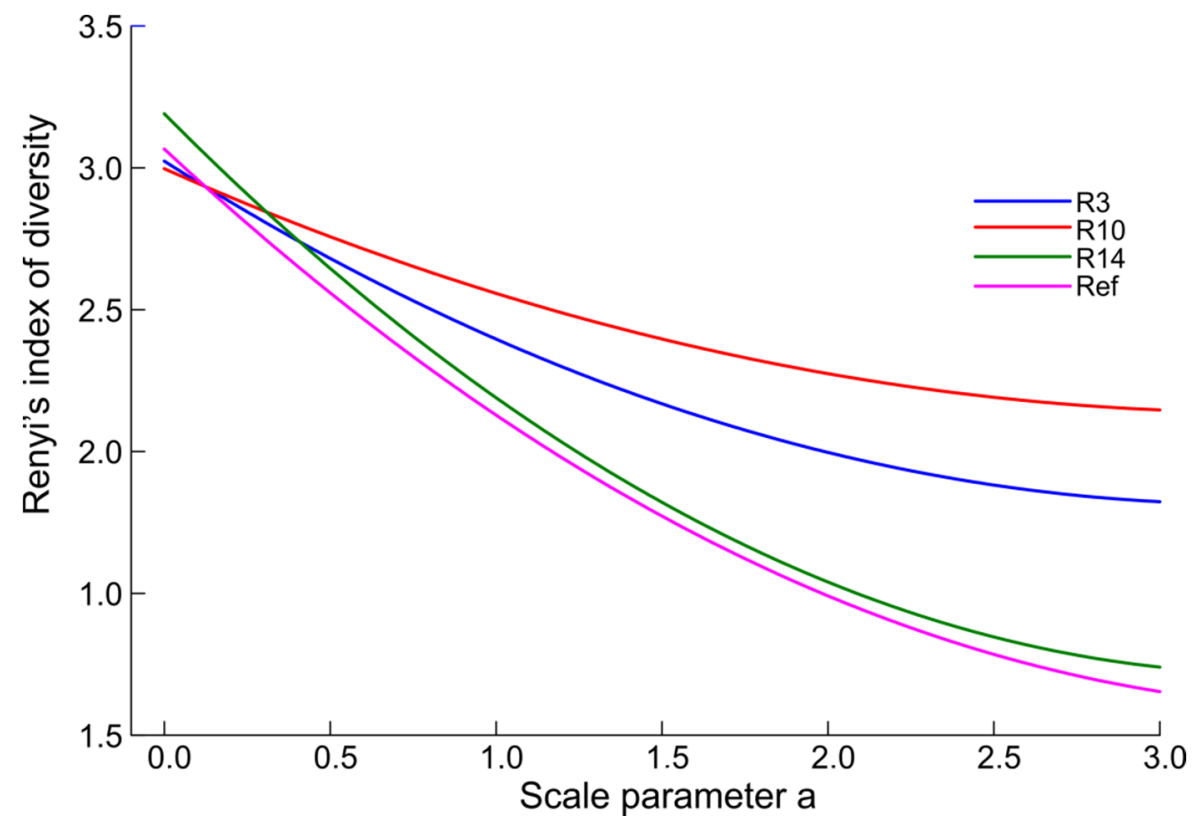

Figure 4. Diversity profiles of nematode communities in the three reclaimed sections (R3, R10 andR14) and references sites (Ref). For $a=0,1$ and 2, the index is equal to the genus richness, Shannon index and Simpson index, respectively. 


\subsection{Architecture of the Network}

The networks at R3 and R10 had higher densities and shorter distances between the nodes compared to R14 and the reference sites (Table 3).

Table 3. Network parameters in the three reclaimed sections (R3, R10 and R14) and references sites (Ref). Stars show significant differences compared to corresponding average estimations made in 999 random networks with the same number of links. ${ }^{* * *} p<0.001,{ }^{* *} p<0.01,{ }^{*} p<0.05$.

\begin{tabular}{cccccc}
\hline Network Variables & Metrics & R3 & R10 & R14 & Ref \\
\hline \multirow{2}{*}{ Cohesion } & Density $\left(\mathrm{D}_{\text {real }}\right)$ & 0.39 & 0.43 & 0.31 & 0.28 \\
& Shortest path $\left(\mathrm{L}_{\text {real }}\right)$ & 1.45 & 1.34 & 1.57 & 1.74 \\
& Clustering coefficient $\left(\mathrm{Cl}_{\text {real }}\right)$ & $0.74^{* *}$ & $0.78^{* *}$ & $0.66^{* * *}$ & $0.59^{* * *}$ \\
\hline \multirow{4}{*}{ Modularity } & Small-world-ness $(\mathrm{S})$ & $1.16^{*}$ & $1.21^{*}$ & $1.55^{* *}$ & $2.14^{* * *}$ \\
& E-I & 0.60 & 0.42 & 0.49 & 0.27 \\
& Out-centrality (\%) & 30.77 & 24.87 & 36.13 & 30.48 \\
& In-centrality $(\%)$ & 20.82 & 20.25 & 11.04 & 9.75 \\
\hline
\end{tabular}

The corresponding values calculated for the community in R14 converged to those in the reference sites. The shortest path values in the real networks were similar to those in the random networks, providing the first indication of small-world networks. The concept of small-worldness was further supported by the clustering coefficient values. The clustering coefficient was significantly higher in the real networks compared to random. In all cases, the $S$ index values were higher than unity, implying small-world architecture. The degree values ranged between 24 and 36, and 10 and 21\%, for out and in centralities, respectively, showing moderate average importance (out centrality) and a low influence (in centrality; Table 3).

To validate the modular architecture, we tested whether our data were consistent with the distribution of nodes in structurally equivalent classes by estimating the R-square correlation coefficient. The analysis output was positive for all four networks. The R-square index was highly significant, and the nodes were classified into five classes of structural equivalence. Positive E-I values were calculated for all the classes with more external links than internal links.

Two main clusters out of five showed high density, high levels of connectivity and nodes with high out centrality (Figure 5a-d, Table 4). As succession progressed, the average density of structurally equivalent classes dropped progressively, with the R14 network ranging from 0.49 to 0.70 (link/node).

Table 4. Means of density and effective size recorded in the first two clusters of ecological equivalence (descending average density). Coefficients of variation ( $\mathrm{CV} \%$ ) for out-centrality and effective size are also shown. Significant differences in comparison to corresponding average estimations made in 999 random networks with the same number of links are shown by stars: ${ }^{*} p<0.01, * p<0.05$.

\begin{tabular}{cccc}
\hline Sampling Sites & Metrics & Cluster 1 & Cluster 2 \\
\hline \multirow{2}{*}{ R3 } & Density & 0.82 & 0.74 \\
& \% CV out-centrality & 14.15 & 21.42 \\
& Effective size (CV\%) & $8.08(11)$ & $6.04^{* *}(15)$ \\
\hline \multirow{2}{*}{ R10 } & density & 0.94 & 0.77 \\
& \% CV out-centrality & 14.08 & 38.15 \\
& Effective size (CV\%) & $7.60(25)$ & $5.47^{* *}(21)$ \\
\hline \multirow{2}{*}{ R14 } & Density & 0.70 & 0.49 \\
& \% CV out-centrality & 20.85 & 27.06 \\
& Effective size (CV\%) & $13.04 *(23)$ & $7.22 * *(30)$ \\
\hline \multirow{2}{*}{ Reference sites } & Density & 0.83 & 0.81 \\
& \% CV out-centrality & 52.52 & 45.79 \\
& Effective size (CV\%) & $8.66^{*}(34)$ & $5.87 *(48)$ \\
\hline
\end{tabular}



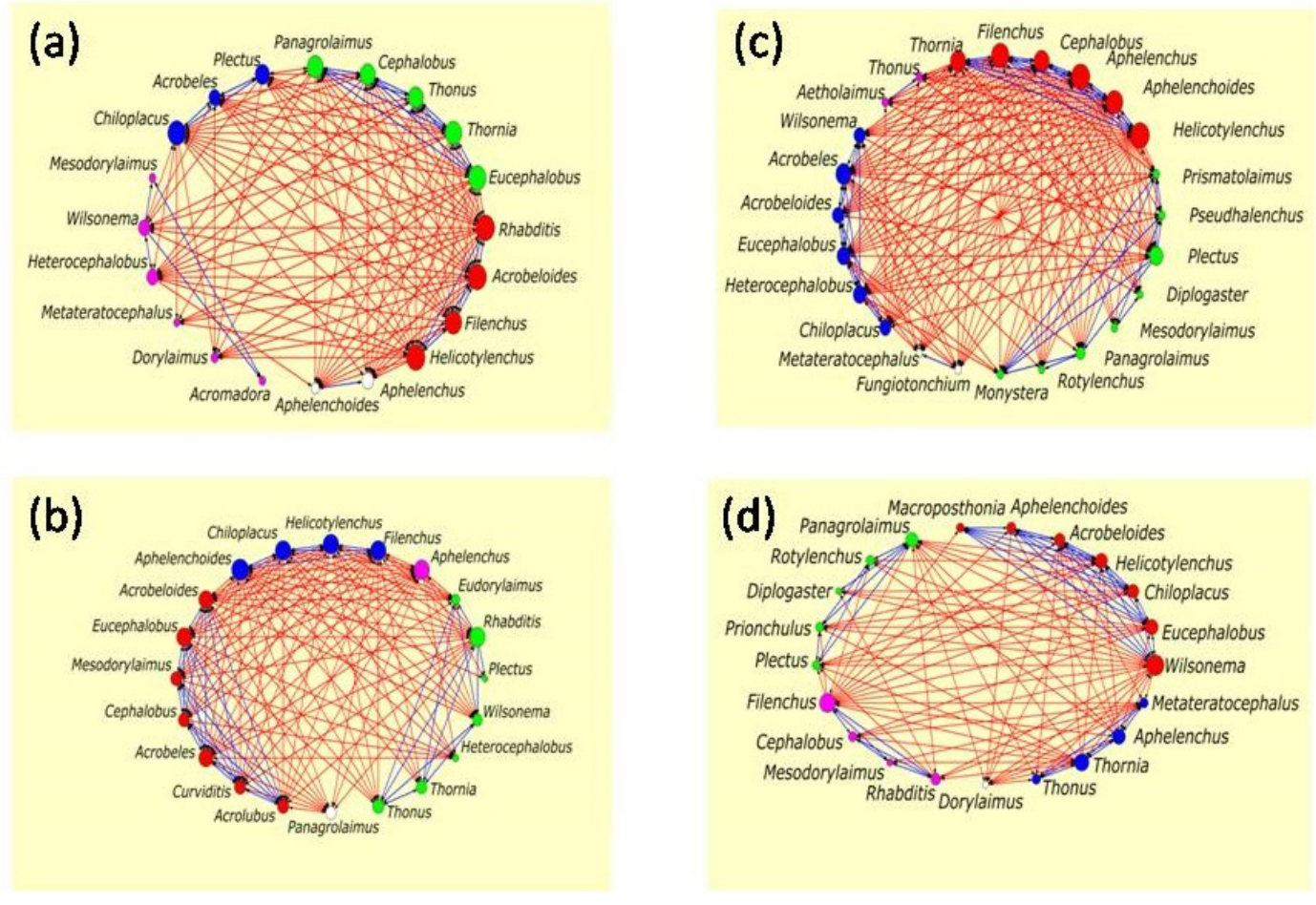

Figure 5. (a-d) Networks of relationships among the nematode genera in the reclaimed landfill sections: (a) R3, (b) R10, (c) R14 and (d) reference sites (Ref). Nodes were ordered by the class of structural equivalence and plotted in a circular format. Different colors correspond to different classes of structural equivalence, while the size of each node represents its out-centrality. Red-colored lines represent links between classes of structural equivalence, while blue-colored lines correspond to links within classes of structural equivalence.

The nodes of the first main cluster from the R14 and reference networks had significantly greater mean effective sizes than those from the random networks. This was not the case for the corresponding values of the R3 and R10 networks. For the second main cluster, the effective mean size was significantly lower in all the networks compared to those estimated in the random networks (Table 3). The coefficient of variation (CV\%) for effective size and out-centrality was higher in the two main clusters of the reference network compared to the corresponding values in the R3, R10 and R14 clusters.

At the reference sites, the classes of structural equivalence mainly consisted of genera belonging to different trophic guilds (Figure S1). In comparison, bacterivorous nematodes at reclaimed sites tended to exhibit similar trophic profiles. In fact, in the R3 community, three bacterivores formed a separate class (Plectus, Acrobeloides and Chiloplacus). In the R10 community, six out of the seven members of the red-colored class were bacterivores. In the R14 community, all six genera in the blue-colored class were bacterivores. Finally, the omnivores Thornia and Thonus in the three communities, and Eudorylaimus inthe unique community where it was present, were classified in the same class of structural equivalence, representing a similar profile of relationships. The same held for the plant parasite Helicotylenchus and the root browser Filenchus in three out of the four communities.

\section{Discussion}

\subsection{Abundance, Diversityand Faunal Indices}

A fairly constant number of genera was recorded along the reclaimed and reference sites, which was likely attributed to the transported soils that were used to cover the saturated sections of the landfill. Soil was obtained from a nearby natural system that supplied the initial pool of nematode genera. In fact, the pools of genera in R3 and the reference sites were almost identical. Differences were only recorded 
for Acrobeles and five other extremely rare genera. Thus, the differences in community composition between the R3 and reference communities were due to changes in the percent participation of genera.

Abundance increased with the number of years of recovery, converging with that of the reference communities in this study, reflecting that of other restoration projects. This phenomenon was attributed to changes in vegetation cover [9], litter and humus accumulation, and the soil's physicochemical properties $[7,11,44]$. Despite the number and identity of genera being comparable, our results (Table 2) showed dissimilarities in community composition during the early and mid-succession stages and a shift in the Renyi diversity index during transition from R10 to R14. The abundance decreased from R3 to R10, followed by a significant increase from R10 to R14. The irregularity in the succession trajectory supported the results of Hohberg [11] in mine spoil areas and Kardol et al. [8] in abandoned arable lands. Across sites, the structure index (SI) was less than 40, while the enrichment index (EI) ranged from 36 to 53. Thus, basal or degraded food webs and depleted soils were dominated by bacterial decomposition channels [31]. The evolution of the trophic structure of the nematode community deviated from the concept of progressive improvement and followed a rather idiosyncratic response. A similar finding was obtained by Hohberg [11]. The behavior of the weighted faunal indices and the complexity of food web interactions did not continuously change from younger successional stages to older stages (Figure 2). The channel index was an exception, showing a monotonous increase over time.

\subsection{Network Analysis}

In all four networks, the value of parameter $S$ was greater than unity, indicating a modular architecture and small-world properties. Small-world networks resembled random networks at the level of the entire network, where asthe configuration of the interactions among members within clusters resembled those of non-random networks [41,45]. The values of parameters pertaining to the entire network configuration (namely $\mathrm{D}_{\text {real }}$ and $\mathrm{L}_{\text {real }}$ ) did not differ from randomness. This resulted in rather random spatial arrangements of genera and interactions between each other in the experimental sites. By contrast, the values of $\mathrm{Cl}_{\text {real }}$ represented the level of individual clusters deviating from randomness. Furthermore, the low to moderate values of the out- and in-degree centralities showed regular distributions of interactions among genera within structurally equivalent clusters (absence of hub genera). Because the Mij index of Mac Arthur and Levins [33] represented spatial coexistence, it is interesting to relate the properties of small-worldness to field conditions. At the level of the entire network, the increased number of internal and external links between the genera of the main clusters indicated the spatial coexistence of nematode genera over a wide range of different sampling areas in which variation in conditions was mainly induced by heterogeneity in vegetation. Nematode dispersal in the restored sites of Tagarades was facilitated by regular irrigation, which resulted in sufficient fluidity of the groundwater. Zhou et al. [46] suggested that the easy dispersal of organisms between local sites of similar abiotic conditions is a random process. Thus, the water supply in restored sections might generate a permanent source of randomness that was captured at the level of the entire network of interactions.

At the level of clusters, the genera of each class of structural equivalence should be ecologically equivalent with respect to the exploitation of resources or environmental constraints $[13,47]$. This hypothesis assumes extensive overlap in the response of genera to abiotic and biotic constraints, including the temperature, humidity, soil $\mathrm{pH}$, availability of food and space. These overlapping niche traits control the intensity of density-dependent processes (fecundity, mortality, duration of development predation, competition, etc.).

Thus, in all four networks, some metrics were assigned to randomness, while others were assigned to regularity. We evaluated the relative importance of these metrics for each phase of succession based on information on the effective size of genera, cluster connectivity and density-dependent interactions. These parameters are thought to influence the balance between stochastic and deterministic processes regulating the structure of the community [46]. 


\subsection{The Succession Trajectory}

\subsubsection{Reference Sites}

The abundance of communities in the reference sites was high, with low diversity and a lack of dominance between genera representing a rather balanced food web $(\mathrm{CI} \approx 50 \%)$. By contrast, the high $S$ value in network showed well-organized functional clusters characterized by the dominance of internal versus external links. In addition, the low density ( $\left.D_{\text {real }}\right)$ showed few direct interactions, while the long distance between nodes $\left(\mathrm{L}_{\text {real }}\right)$ implied the strong presence of indirect relationships. These characteristics illustrate a reference community with high complexity in interactions [31,48].

Individual clusters included members of different trophic guilds in our study, suggesting the fine-scale partition of resources [49], favoring a large number of multitrophic links within clusters. In addition, the two main functional clusters of the reference network contained genera that were present in high abundance (Figure S1), indicating that both intra- and inter-density-dependent interactions were enhanced. Additionally, these clusters exhibited a high density of interactions, implying enhanced local connectivity between genera within the main functional clusters. This phenomenon reflects a high availability of resources $[50,51]$. The high availability of resources reflected the well-developed and diverse vegetation cover of the reference sites [21]. High variation in the effective size (impact) of nodes recorded in the two main reference clusters suggests the co-existence of focal genera that strongly impact non-focal (satellite) genera. Focal genera are expected to influence the growth of other genera, thus shaping the community in a similar way to early colonizers. In conjunction with the habitat filtering induced by diverse vegetation, the existence of focal genera and density-dependent interactions might reflect strong deterministic regulation within local communities [52].

\subsubsection{Reclaimed Sites}

The networks in the early- and mid-successional stages (R3 and R10) had lower heterogeneity. On the level of the entire network, $\mathrm{D}_{\text {real }}$ progressively increased and $\mathrm{L}_{\text {real }}$ decreased, which meant more direct interactions and a progressive decline in network complexity from R3 to R10. On the level of clusters, certain classes of structural equivalence were identified that contained specific trophic guilds, with simpler food relationships dominated by bacterivores. Since the members of each class of structural equivalence should be ecologically equivalent with respect to the exploitation of resources or environmental constraints [13,47], it is likely that the modularity of these networks originated from a strict spatial separation of vegetation patches [21] and might have also been accompanied by a strict distribution of resources.

Compared to the reference network, the S-values in R3 and R10 were lower, with a strong presence of external links (E-I index); consequently, these clusters were not as tightly organized as the reference network. Lower nematode abundance compared to the reference sites indicated the presence of fewer density-dependent interactions. This finding combined with lower variation $(\mathrm{CV} \%)$ in out-centrality and effective size compared to the reference sites indicates that the importance of genera was more equally distributed in the same cluster. This phenomenon weakened deterministic regulation, particularly in R10. The trends were reversed in R14, and the architecture of the interactions approached that in the reference sites. Thus, 14 years after the closure of the landfill, the structural complexity in the interactions tended to converge towards that of the reference community. However, it is noteworthy that the centrality of the nodes is consistent with the succession trajectory described by Ruess and Ferris [5], in that the different succession stages have specific nematode assemblages, which comply with the types of decomposing material. Indeed, in R3 and R10 sites with a predominance of fast cycle processes, the enrichment opportunist Rhabditis and certain general opportunist Cephaloiidae such as Acrobeloides, Chilopacus and Eucephalobus held the most central positions. Additionally, Helicotylenchus and Filenchus occupied central positions. In R14 sites with predominating slow cycle processes, in addition to Helicotylenchus and Filenchus, relatively high centrality values also displayed the fungivores Aphelenchus and Aphelenchoides. In these sites was also recorded the highest value for 
the channel index $(>50 \%)$, suggesting the predominance of the fungal decomposition channels. In the reference sites, only Filenchus and Wilsonema occupied the most central positions in the network, while the CI values showed balanced decomposition channels. Thus, contrary to architectural complexity in interactions, 14 years after the closure of the landfill, the complexity of the food web did not exhibit convergence towards the reference sites.

Compared to the reference and R14 networks, the processes that modulated the architecture in networks R3 and R10 were closer to the stochastic end point of the deterministic-stochastic continuum. The low shortest path in the R3 and R10 network combined with the less complex food web showed how easily the consequences of hazardous environmental constraints could spread across the whole network. Although globally robust against environmental constraints, the structural features of the monotrophic clusters in the R3 and R10 networks showed that any changes to the relationship among genera were expected to be more abrupt and radical than those in the R14 and reference networks [46]. In the R14 and reference networks, the likelihood of precipitous change was expected to be moderate, due to the well-organized multitrophic clusters making up the more complex food web. Scheffer et al. [53] considered these spatially clustered communities to be relatively resistant, exhibiting only subtle changes after disturbance due to local recovery; however, these communities are prone to critical transitions.

\section{Conclusions}

Through evaluating community composition, food web structure and the architecture of the relationships between genera, we showed how nematode communities are structured during succession. Some variables such as community composition, abundance and diversity converged to those in the reference sites. The network parameters (shortest path, clustering coefficient and Worldness index) tended to converge, while the Enrichment and Channel indices did not. Only the Channel index and Worldness index showed linear responses with the succession time. Across all the successional stages, the resource status remained basal or degraded and the networks displayed modularity, with random features on the level of the entire network but non-random features in structurally equivalent clusters. These two patterns enhanced the ability of the nematode communities to cope with sudden changes due to their capacity for local recovery.

Supplementary Materials: The following are available online at http://www.mdpi.com/1424-2818/12/7/274/s1. Figure S1: Ranking of genera according to their abundance recorded in the different successional stages (R3, R10 and R14) and the references sites as well. The letter above each column corresponds to the genus c-p-value, Table S1: The most abundant herbaceous species recorded in reclaimed and reference sites (Papatheodorou et al. 2019), Table S2: Results of one-way ANOVA applied on Channel Index, Table S3: Results of one-way ANOVA applied on Enrichment Index, Table S4: Results of one-way ANOVA applied on Plant Parasite Index, Table S5: Results of one-way ANOVA applied on Maturity Index, Table S6. Results of one-way ANOVA applied on Structural Index.

Author Contributions: Conceptualization, G.P.S. and E.M.P.; formal analysis, G.P.S.; investigation, I.R.-P.; methodology, G.B.; supervision, E.M.P.; writing—original draft, G.P.S. and P.K.; writing—review and editing, G.P.S., M.D.A. and E.M.P. All authors have read and agreed to the published version of the manuscript.

Funding: This research received no external funding.

Acknowledgments: I would like to thank Gail Schofield for her valuable contribution to the linguistic editing of the manuscript.

Conflicts of Interest: The authors declare no conflict of interest.

\section{References}

1. Putman, R.J. Community Ecology; Kluwer Academic Publishers: Dordrecht, The Netherlands, 1994; pp. 1-178.

2. Pickett, S.T.A.; McDonnell, M.J. Changing perspectives in community dynamics: A theory of successional forces. Trends Ecol. Evol. 1989, 4, 241-245. [CrossRef]

3. Pickett, S.T.A.; Meiners, S.J.; Cadenasso, M.L. Domain and propositions of succession theory. In The Theory of Ecology; Scheiner, S.M., Willig, M.R., Eds.; University of Chicago Press: Chicago, IL, USA, 2011; pp. $185-218$. 
4. Yeates, G.W. Nematodes as soil indicators: Functional and biodiversity aspects. Biol. Fertil. Soils 2003, 37, 199-210. [CrossRef]

5. Ruess, L.; Ferris, H. Decomposition pathways and successional changes. Nematol. Monogr. Perspect. 2004, 2, 547-556.

6. Hanel, L. Recovery of soil nematode populations from cropping stress by natural secondary succession to meadow land. Appl. Soil Ecol. 2003, 22, 255-270. [CrossRef]

7. Hanel, L. Nematode assemblages indicate soil restoration on colliery spoils afforested by planting different tree species and by natural succession. Appl. Soil Ecol. 2008, 40, 86-99. [CrossRef]

8. Kardol, P.; Bezemer, T.M.; van der Wal, A.; van der Putten, W.H. Successional trajectories of soil nematode and plant communities in a chronosequence of ex-arable lands. Biol. Conserv. 2005, 126, 317-332. [CrossRef]

9. Dmowska, E.; Ilieva-Makulec, K. Secondary succession of nematodes in power plant ash dumps reclaimed by covering with turf. Eur. J. Soil Biol. 2006, 42, 164-170. [CrossRef]

10. Bongers, T.; Ferris, H. Nematode community structure as a bioindicator in environmental monitoring. Trends Ecol. Evol. 1999, 14, 224-228. [CrossRef]

11. Hohberg, K. Soil nematode fauna of afforested mine sites: Genera distribution, trophic structure and functional guilds. Appl. Soil Ecol. 2003, 22, 113-126. [CrossRef]

12. Wasilewska, L. Changes in the structure of the soil nematode community over long-term secondary grassland succession in drained fen peat. Appl. Soil Ecol. 2006, 32, 165-179. [CrossRef]

13. Zhou, J.; Deng, Y.; Luo, F.; He, Z.; Tu, Q.; Zhi, X. Functional molecular ecological networks. Am. Soc. Microb. 2010, 1, e00169-10. [CrossRef] [PubMed]

14. Ruiz-Jaén, M.; Aide, T. Restoration success: How is it being measured? Restor. Ecol. 2005, 13, 569-577. [CrossRef]

15. Kim, K.D.; Lee, E.J. Potential tree species for use in the restoration of unsanitary landfills. Environ. Manag. 2005, 36, 1-14. [CrossRef] [PubMed]

16. Proulx, S.R.; Promislow, D.E.L.; Phillips, P.C. Network thinking in ecology and evolution. Trends Ecol. Evol. 2005, 20, 345-353. [CrossRef] [PubMed]

17. Stamou, G.P.; Monokrousos, N.; Gwynn-Jones, D.; Papatheodorou, E.M. A polyphasic approach for assessing eco-system connectivity demonstrates that perturbation remodels network architecture in soil microcosms. Micr. Ecol. 2019, 78, 949-960. [CrossRef]

18. Zhang, F.; Gao, C.; Wang, J.; Lu, Y.; Shen, Z.; Liu, T.; Chen, T.; Ran, W.; Shen, Q. Coupling sugarcane yield to soil nematodes: Implications from different fertilization regimes and growth stages. Agric. Ecosyst. Environ. 2017, 247, 157-165. [CrossRef]

19. Kapagianni, P.D.; Boutsis, G.; Argyropoulou, M.D.; Papatheodorou, E.M.; Stamou, G.P. The network of interactions among soil quality variables and nematodes: Short term responses to disturbances induced by chemical and organic disinfection. Appl. Soil Ecol. 2010, 44, 67-74. [CrossRef]

20. Papatheodorou, E.M.; Hatzoudis, G.; Kapagianni, P.; Tsiripidis, I.; Stamou, G.P. Social network analysis as a tool for the study of ecological succession route in reclaimed landfills. Res. Plant. Sci. 2019, 7, 1-10.

21. Chatzoudis, G. Assessment of Soil Parameters and Vegetation in Restored Sites of Tagarades Landfill. Master's Thesis, AUTh University Thessaloniki, Thessaloniki, Greece, 2012. (In Greek with an English Summary).

22. S'Jacob, J.J.; van Bezooijen, J. A Manual for Practical Work in Nematology; Department of Nematology, Wageningen Agricultural University: Wageningen, The Netherlands, 1984.

23. Bongers, T. De Nematoden van Nederland; Koninklijke Nederland se Natuurhistorische Vereniging: Utrecht, The Netherlands, 1994.

24. Patil, G.P.; Taillie, C. An overview of diversity. In Ecological Diversity in Theory and Practice; Grassle, J.F., Patil, G.P., Smith, W., Taillie, C., Eds.; International Cooperative Publishing House: Cham, Switzerland; Fairland, MD, USA, 1979; pp. 3-27.

25. Rényi, A. Proceedings of the 4th Berkeley Symposium on Mathematical Statistics and Probability. In On Measures of Entropy and Information; Neyman, J., Ed.; University of California Press: Cham, Switzerland, 1961; pp. 547-561.

26. Ricotta, C. From theoretical ecology to statistical physics and back: Self similar landscape metrics as a synthesis of ecological diversity and geometrical complexity. Ecol. Model. 2000, 125, 245-253. [CrossRef] 
27. Tóthmérész, B. Comparison of different methods for diversity ordering. J. Veg. Sci. 1995, 6, $283-290$. [CrossRef]

28. Yeates, G.W.; Bongers, T.; de Goede, R.G.M.; Freckman, D.W.; Georgieva, S.S. Feeding habits in nematode families and genera-an outline for soil ecologists. J. Nematol. 1993, 25, 315-331.

29. Bongers, T. The maturity index: An ecological measure of environmental disturbance based on nematode species composition. Oecologia 1990, 83, 14-19. [CrossRef]

30. Bongers, T.; Bongers, M. Functional diversity of nematodes. Appl. Soil Ecol. 1998, 10, 239-251. [CrossRef]

31. Ferris, H.; Bongers, T.; de Goede, R.G.M. A framework for soil food web diagnostics: Extension of the nematode faunal analysis concept. Appl. Soil Ecol. 2001, 18, 13-29. [CrossRef]

32. Butts, C.T. A relational event framework for social action. Sociol. Methodol. 2008, 38, 155-200. [CrossRef]

33. MacArthur, R.; Levins, R. The limiting similarity convergence and divergence of coexisting species. Am. Nat. 1967, 101, 377-385. [CrossRef]

34. Cancela da Fonseca, J.P.; Vannier, G. Echantillonnage de Microarthropodes du Sol. In Problemes d' Ecologie: L' Echantillonnage des Peuplements animaux des Milieu Terrestres; Bourliere, L., Ed.; Masson et Cie: Paris, France, 1969; pp. 207-235.

35. Borgatti, S.P.; Everett, G.; Freeman, L.C. UCINET 5.0 Version 1.00; Computer Manual; Analytech Technologies: Natick, MA, USA, 1999.

36. Borgatti, S.P. NetDraw Software for Network Visualization; Analytic Technologies: Lexington, KY, USA, 2002.

37. Huisman, M.; Van Duijn, M.A.J. Software for Social Network Analysis. In Models and Methods in Social Network Analysis; Carrington, P.J., Scott, J., Wasserman, S., Eds.; Cambridge University Press: New York, NY, USA, 2005; pp. 270-316.

38. O'Malley, A.J.; Marsden, V.P. The analysis of social networks. Health Serv. Outcomes Res. Methodol. 2008, 8, 222-269. [CrossRef]

39. Borrett, S.R.; Moody, J.; Edelmann, A. The rise of Network Ecology: Maps of the topic diversity and scientific collaboration. Ecol. Model. 2014, 10, 111-127. [CrossRef]

40. Burt, R.S. Structural holes and good ideas. Am. J. Sociol. 2004, 110, 349-399. [CrossRef]

41. Humphries, M.D.; Gurney, K. Network 'small-world-ness': A quantitative method for determining canonical network equivalence. PLoS ONE 2008, 3, e0002051. [CrossRef]

42. Hanneman, R.A.; Riddle, M. Introduction to Social Network Methods. Available online: http://faculty.ucr. edu/ \{\}hanneman (accessed on 13 April 2020).

43. Krackhardt, D.; Stern, R. Informal networks and organizational crises-An experimental simulation. Soc. Psychol. Q. 1988, 51, 123-140. [CrossRef]

44. Hu, N.; Li, H.; Tang, Z.; Li, Z.; Tian, J.; Lou, Y.; Li, J.; Li, G.; Hu, X. Community diversity, structure and carbon footprint of nematode food web following reforestation on degraded Karst soil. Sci. Rep. 2016, 6, 28138. [CrossRef] [PubMed]

45. Sinha, S. Complexity vs stability in small-world networks. Phys. A 2005, 346, 147-153. [CrossRef]

46. Zhou, J.; Deng, Y.; Zhang, P.; Xue, K.; Liang, Y.; van Nostrand, J.D.; Yang, Y.; He, Z.; Wu, L.; Stahl, D.A.; et al. Stochasticity, succession, and environmental perturbations in a fluidic ecosystem. Proc. Natl. Acad. Sci. USA 2014, 111, E836-E845. [CrossRef] [PubMed]

47. Kurvers, R.H.J.M.; Krause, J.; Croft, D.P.; Wilson, A.D.M.; Wolf, M. The evolutionary and ecological consequences of animal social networks: Emerging issues. Trends Ecol. Evol. 2014, 29, 326. [CrossRef]

48. Boutsis, G.; Stamou, G.P.; Argyropoulou, M.D. Short term effects of soil disinfection with metham sodium and organic alternatives on nematode communities. Community Ecol. 2011, 12, 161-170. [CrossRef]

49. Albrecht, M.; Gotelli, N.J. Spatial and temporal niche partitioning in grassland ants. Oecologia 2001, 126, 131-141. [CrossRef]

50. Foster, E.A.; Franks, D.W.; Morrell, L.J.; Balcomb, K.C.; Parsons, K.M.; van Ginneken, A.; Croft, D.P. Social network correlates of food availability in an endangered population of killer whales Orcinus orca. Anim. Behav. 2012, 83, 731-736. [CrossRef]

51. Ren, G.; Meng, T.; Ma, Y. Sugars altered fungal community composition and caused high network complexity in a Fusarium wilt pathogen-infested soil. Biol. Fertil. Soils. 2020, 56, 395-409. [CrossRef] 
52. Jiang, Y.; Lei, Y.; Yang, Y.; Korpelainen, H.; Niinemets, U.; Li, C. Divergent assemblage patterns and driving forces for bacterial and fungal communities along a glacier forefield chronosequence. Soil Biol. Biochem. 2018, 118, 207-216. [CrossRef]

53. Scheffer, M.; Carpenter, S.R.; Lenton, T.M.; Bascompte, J.; Brock, W.; Dakos, V.; van de Koppel, J.; van de Leemput, I.A.; Levin, S.A.; van Nes, E.H.; et al. Anticipating critical transitions. Science 2012, 338, 344-348. [CrossRef] [PubMed]

C 2020 by the authors. Licensee MDPI, Basel, Switzerland. This article is an open access article distributed under the terms and conditions of the Creative Commons Attribution (CC BY) license (http://creativecommons.org/licenses/by/4.0/). 